\title{
4A's Treatment Protocol
}

National Cancer Institute

\section{Source}

National Cancer Institute. 4A's Treatment Protocol. NCI Thesaurus. Code C16161.

A smoking cessation strategy recommended by the National Cancer Institute. The first ' $A$ ' is to ask patients about their smoking status at every visit and record this information. The second ' $\mathrm{A}$ ' is to advise smokers to quit. The third ' $\mathrm{A}$ ' is to assist patients' cessation attempts where possible by helping them to set a quit date, providing self-help materials, prescribing pharmacological treatment, and recommending counseling. The final ' $\mathrm{A}$ ' is to arrange follow-up contact. (from Medscape) 